\title{
Comparative effects of magnetic and water-based hyperthermia treatments on human osteosarcoma cells
}

This article was published in the following Dove Press journal: International Journal of Nanomedicine

\author{
Dumitru-Daniel Herea ${ }^{1, *}$ \\ Camelia Danceanu ${ }^{1,2, *}$ \\ Ecaterina Radu',2,* \\ Luminita Labusca ${ }^{1,3, *}$ \\ Nicoleta Lupu',* \\ Horia Chiriac ${ }^{1, *}$ \\ 'MDM Department, National Institute \\ of Research and Development for \\ Technical Physics, lasi, Romania; \\ 2University "Al I Cuza," University \\ of lasi, lasi, Romania; ${ }^{3}$ Systems \\ Biomedical Informatics and Modeling \\ (SBIM), Frankfurt, Germany \\ *These authors contributed equally \\ to this work
}

\begin{abstract}
Introduction: Hyperthermia (HT) based on magnetic nanoparticles (MNPs) represents a promising approach to induce the apoptosis/necrosis of tumor cells through the heat generated by MNPs submitted to alternating magnetic fields. However, the effects of temperature distribution on the cancer cells' viability as well as heat resistance of various tumor cell types warrant further investigation. Methods: In this work, the effects induced by magnetic hyperthermia (MHT) and conventional water-based hyperthermia (WHT) on the viability of human osteosarcoma cells at different temperatures $\left(37^{\circ} \mathrm{C}-47^{\circ} \mathrm{C}\right)$ was comparatively investigated. Fe-Cr-Nb-B magnetic nanoparticles were submitted either to alternating magnetic fields or to infrared radiation generated by a water-heated incubator.

Results: In terms of cell viability, significant differences could be observed after applying the two HT treatment methods. At about equal equilibrium temperatures, MHT was on average $16 \%$ more efficient in inducing cytotoxicity effects compared to WHT, as assessed by MTT cytotoxicity assay.

Conclusion: We propose the phenomena can be explained by the significantly higher cytotoxic effects initiated during MHT treatment in the vicinity of the heat-generating MNPs compared to the effects triggered by the homogeneously distributed temperature during WHT. These in vitro results confirm other previous findings regarding the superior efficiency of MHT over WHT and explain the cytotoxicity differences observed between the two antitumor HT methods.
\end{abstract}

Keywords: magnetic hyperthermia, water-based hyperthermia, magnetic nanoparticles, cancer cells

\section{Introduction}

Within the context of multimodal therapies for the treatment of solid malignancies, hyperthermia (HT) is considered as adjuvant therapy the first applications of which can be traced back to the beginning of the 20th century. Local HT has been defined as an antitumor treatment modality based essentially on the increase of tumors' temperature through the heat generated inside the tumor cells or transferred within cells from a heated environment. HT can be based on microwaves, radiofrequency energy, ultrasound, infrared radiators, and different hot sources (eg, hot water, magnetic nanoparticles, and resistive implants). ${ }^{1}$ However, the most studied HT method for medical applications is by far magnetic hyperthermia based on magnetic nanoparticles prepared by different physical and chemical methods. ${ }^{2-6}$

Treatment efficiency is mainly influenced by the heating time and temperature levels achieved during the HT process, the lethal effect depending on the temperature induced in the targeted regions, exposure time to heat, ${ }^{1}$ and type of cancer cells.
Correspondence: Dumitru-Daniel Herea National Institute of Research and Development for Technical Physics, 47 Mangeron Avenue, lasi, RO 700050, Romania

Email dherea@phys-iasi.ro 
During HT treatment, cancer cells are subjected to a heating process that leads to protein denaturation, heat shock protein production, specific immunomodulation, and DNA cross-linking, eventually leading to cell death by apoptosis/necrosis (cell death). ${ }^{7,8}$ On the contrary, normal cells are less sensitive to heat and, therefore, their survival rate is higher.

Recent literature has revealed controversies regarding the efficiency of different HT methods in inducing tumor cells' death. Several research groups have shown that for identical treatment temperature, magnetic hyperthermia (MHT) affected the cancer cells more efficiently compared with conventional hot water hyperthermia (WHT). ${ }^{9}{ }^{10}$ By contrast, other groups found convincing evidence that the two methods are equivalent in reducing tumor cell viability. ${ }^{11,12}$

Rodríguez-Luccioni et a $1^{9}$ quantified the cytotoxicity differences induced by MHT and WHT on two cancer cell lines, ie, Caco-2 (human epithelial colorectal adenocarcinoma) and MCF-7 (human breast cancer). In their experiments, MHT induced more efficiently the cellular death in both tumor cells types. The mechanisms for the observed differences between the two HT methods remained unexplained. ${ }^{9}$ Also, Sanz et $\mathrm{al}^{10}$ obtained strong evidence, in terms of temperature efficiency, that MHT requires an average temperature lower than that required by WHT to produce comparable cytotoxic effects in similar "micro-tumor-like" environments.

However, Chan et $\mathrm{al}^{11}$ found no significant differences between cytotoxic effects produced by both heating methods on human lung adenocarcinoma cells (A549). Likewise, Wilhelm et a ${ }^{12}$ obtained similar results for human prostatic tumor cells (PC3). Also, even Calatayud et al's ${ }^{13}$ group mentioned above, in another comprehensive work, found no differences in viability of microglial BV2 cells subjected to hyperthermia induced by homogeneous water bath heating or a magnetically triggered one, contradicting apparent results obtained previously in other experimental conditions. ${ }^{10}$ In this work, in order to shed some light on these seemingly inconsistent reports, we tested the comparative efficiency of WHT and MHT delivered by Fe-Cr-Nb-B magnetic nanoparticles with controllable Curie temperature ${ }^{14}$ on commercial human osteosarcoma (hOS), MG-63 cell line (purchased from Sigma-Aldrich company, St Louis, MO, USA). ${ }^{15}$ Additionally, a mechanism explaining the differences in cell viability recorded after exposure to the two HT delivery methods is proposed and argued.

Several studies have previously reported that different cell lines express different sensitivities to heat, depending on tumor cell type. ${ }^{16,17}$ The current study tangentially addresses the resistance to increasing temperature of hOS cell line exposed to both WHT and MHT. Experiments were performed at different temperatures in order to obtain a multiparametric comparison of hOS cytotoxicity induced by the two HT methods.

\section{Experimental section}

Experimental unit - magnetic hyperthermia The heating experiments were performed by using an induction unit (Hüttinger TIG 10/300, Huttinger Elektronik GmbH, Freiburg, Germany) connected to a laboratory-made coil and a chiller equipment with controlled temperature (Julabo, FL4003, Julabo GmbH, Seelbach, Germany). In order to minimize the heat exchange with laboratory environment, the samples were placed inside a homemade polystyrene box (Figure 1). The samples were placed in the coil and subjected to alternating magnetic fields of $186 \mathrm{kHz}$ and $21 \mathrm{mT}$. Temperature of the samples was measured every 10 seconds by using a fiber optical thermometer (OptoCon AG, FOTEMP4-19, Dresden, Germany).

\section{Preparation of Fe-Cr-Nb-B MNPs}

MNPs were prepared by milling Fe-Cr-Nb-B amorphous ribbons in oleic acid. Details about the particle preparation are described elsewhere. ${ }^{14}$ Oleic acid was used as surfactant to avoid MNP oxidation and to minimize potential modifications in structural and magnetic properties. MNPs were washed three times with ethanol and $10 \%(\mathrm{w} / \mathrm{v}) \mathrm{NaOH}$ solution, respectively, under ultrasonication, in order to remove the remaining oleic acid from the surface of the milled MNPs and to transform the oleic acid into sodium oleate.

For both hyperthermia experiments, MNPs were sterilized for 20 minutes at $121^{\circ} \mathrm{C}$ by autoclaving (Prestige Medical 2100, Prestige Medical, Blackburn, UK).

\section{Cell culture}

The human osteosarcoma cell line MG-63 was acquired from Sigma-Aldrich and cultivated in Dulbecco's Modified Eagle's Medium (Gibco, Life Technologies, Leicestershire, UK) complemented with $10 \%$ fetal bovine serum and $1 \%$ antibiotic antimycotic solution (Sigma Aldrich). Cells were grown in $75 \mathrm{~cm}^{2}$ flasks with $12 \mathrm{~mL}$ complete medium that was replaced with fresh medium every 2-3 days and maintained in a $95 \%$ humidified incubator at $37^{\circ} \mathrm{C}$ and $5 \% \mathrm{CO}_{2}$. At $90 \%$ confluence, the cells were washed with phosphate-buffered solution and incubated with trypsin-EDTA for 4 minutes at $37^{\circ} \mathrm{C}$ to detach from the flask. After suspending in $10 \mathrm{~mL}$ complete medium, the cell density (cells $/ \mathrm{mL}$ ) and viability 


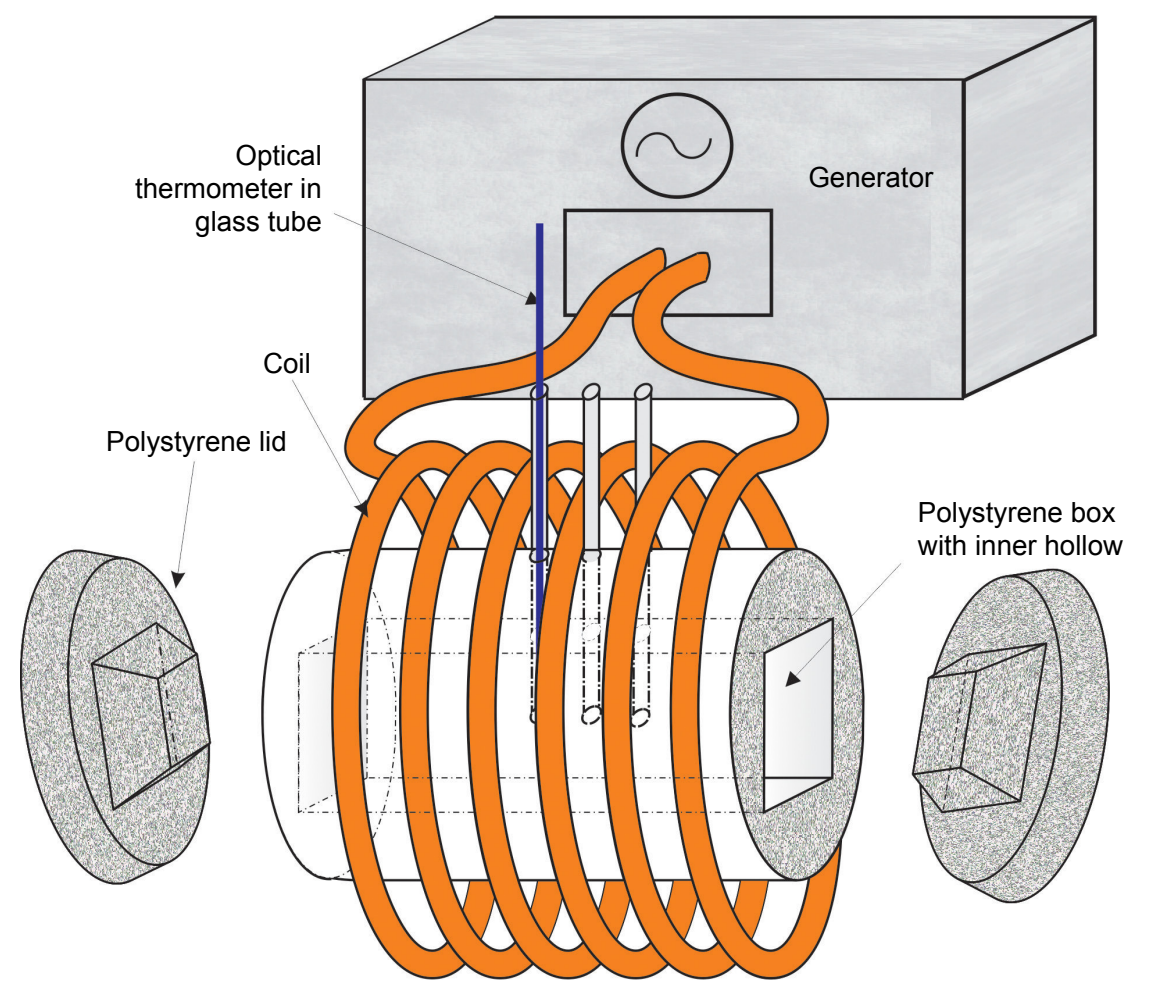

Figure I Schematic drawing of the induction heating unit.

Note: Three optical thermometers were used.

were established by using an automated cell counter (Bio-Rad Laboratories, Hercules, CA, USA).

\section{WHT}

Commercial hOS cells were seeded as monolayer culture in 24-well plates at a density of $2 \times 10^{5}$ cells/well and incubated in a standard incubator for 24 hours at $37^{\circ} \mathrm{C}$ and $5 \% \mathrm{CO}_{2}$.

For WHT, the plates containing osteosarcoma cells, incubated with or without MNPs, were transferred from the standard incubator (from $37^{\circ} \mathrm{C}$ ) inside a laboratory-made incubator (Figure 2) connected to a circulating water bath and placed on the stage of the microscope. Before incubation with cells, the MNPs (5 mg/mL) were dispersed in culture medium by short sonication. After the testing temperature, ranging between $37^{\circ} \mathrm{C}$ and $49^{\circ} \mathrm{C}$, was reached inside the incubator, the WHT treatment was applied for 1 hour. The incubator maintained an almost constant temperature inside for each tested value.

After WHT treatment, hOS cells were analyzed under a Digital Inverted Fluorescence Microscope (Evos FL, Thermo Fisher Scientific, Waltham, MA, USA - Figure 2).

\section{MHT}

HT based on MNPs and Alternating Magnetic Field (AMF) is intensively explored as a modality to efficiently and safely treat solid tumors. For magnetic hyperthermia, the experiments followed the procedure described for WHT treatment. Briefly, the osteosarcoma cells were cultivated at $37^{\circ} \mathrm{C}$ in a 24 -well plate until reaching $90 \%$ confluence. The culture medium of the cells was replaced with $1 \mathrm{~mL}$ of fresh culture medium containing equal concentrations of $\mathrm{Fe}-\mathrm{Cr}$ $\mathrm{Nb}-\mathrm{B}$ particles. The samples were transferred as quickly as

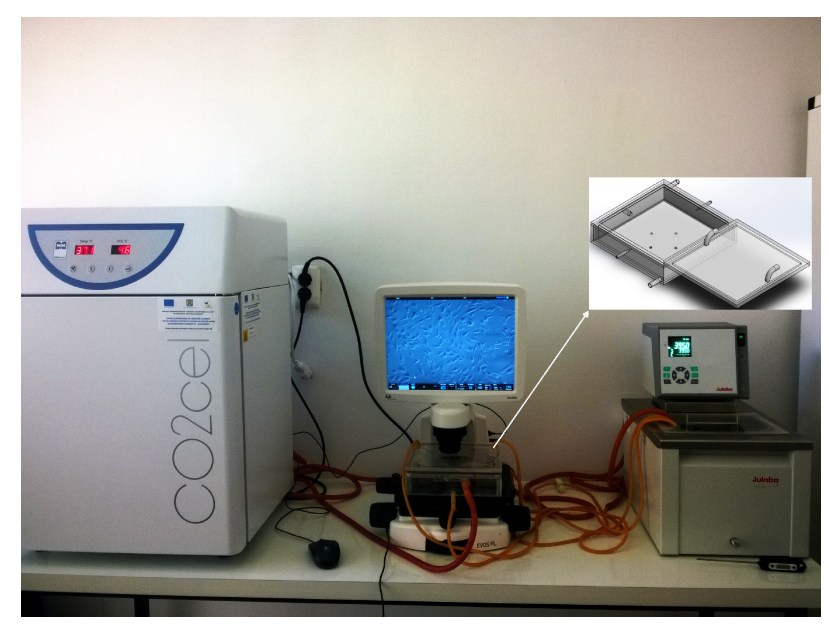

Figure 2 The custom-made incubation system.

Notes: All the six double-sided walls of the incubator were heated by water recirculated by a thermostated bath. For WHT treatment, the $\mathrm{CO}_{2}$ supply of the homemade incubator was discontinued.

Abbreviation: WHT, water-based hyperthermia. 
possible from the standard incubator $\left(37^{\circ} \mathrm{C}\right)$ inside the coil and subjected to AMF for 1 hour.

For both hyperthermia methods, the cytotoxicity was assessed using the MTT assay. The absorbance of the samples was measured at $570 \mathrm{~nm}$ by using a multimode microplate reader (Synergy HTX, BioTek Instruments, Inc., Winooski, VT, USA).

\section{Statistical analysis}

All experiments were performed in triplicate. Statistical analysis was carried out using Student's $t$-test, and expressed as mean \pm SD, using Microsoft Excel 2013 (Microsoft Corporation, Redmond, WA, USA) and Origin 8 software (OriginLab Corporation, Northampton, MA, USA). $P$-values $<0.05$ were considered statistically significant.

\section{Results and discussions}

Osteosarcoma is a lethal disease, extremely resistant to the chemotherapeutic treatment; hOS cell line has a high proliferation rate and is commonly used to model in vitro rapidly expansive and multiple resistant tumor. ${ }^{18}$ The osteosarcomabased experiments were performed using subconfluent culture in the exponential phase growth. Taking into account that osteosarcoma cells present a high proliferation rate, over $90 \%$ confluence was reached in 48 hours in all subcultures.

On the other hand, the magnetic properties of the MNPs along with magnetic field parameters are very important for MHT. MNPs should possess several main properties such as efficient absorption of the AMF energy, biocompatibility, and high potential to accumulate in the tumor volume. ${ }^{19}$ For clinical applications, the AMF frequency should be chosen in the $50 \mathrm{kHz}-10 \mathrm{MHz}$ range, in order to avoid neuromuscular electrostimulation and to tolerate penetration into the body. ${ }^{20}$ AMF with frequencies lower than $1 \mathrm{MHz}$ can heat magnetic materials well, while biological tissues alone are still not heated. ${ }^{21}$ The heat generation of magnetic nanoparticles placed in AMF could be the consequence of the magnetization reversal phenomena in the particle system due to hysteresis processes (ferromagnetic behavior), Néel or Brownian relaxation, and frictional losses in viscous suspensions (superparamagnetic behavior). ${ }^{22}$ The resonance losses and eddy currents can be also considered, but since the resonance relaxations are obvious at very high frequencies, and eddy currents involved in the induced processes of heating are low, they can be both neglected from the heating process. ${ }^{23}$

\section{WHT}

Temperature sensitivity is variable with different cell types. Glioblastoma U87MG and T98G expressed increased levels of Caspase 9 and heat shock protein 90 as markers of induced apoptosis compared to more thermo-tolerant A549 and H1299 lung carcinoma, U87MG breast adenocarcinoma, and PC8 prostate cancer cell lines after 3 days exposure to temperatures ranging from $33^{\circ} \mathrm{C}$ to $40^{\circ} \mathrm{C} . .^{24}$

In this study, we compared the heat sensitivity of hOS cells incubated in a laboratory-made incubator with or without MNPs and subjected to WHT at different treatment temperatures $\left(39^{\circ} \mathrm{C}-49^{\circ} \mathrm{C}\right)$ for 1 hour. Cell viability was evaluated immediately after treatment using the MTT assay.

Tumor cells showed a viability decrease of maximum $10 \%$ for temperatures up to $43^{\circ} \mathrm{C}$ (Figure 3 ). However, after further increase to $49^{\circ} \mathrm{C}$, hOS viability has considerably dropped. There was no statistic difference ( $P=0.91$; two-tails) between the viabilities of cells incubated with MNPs and MNPs-free cells.

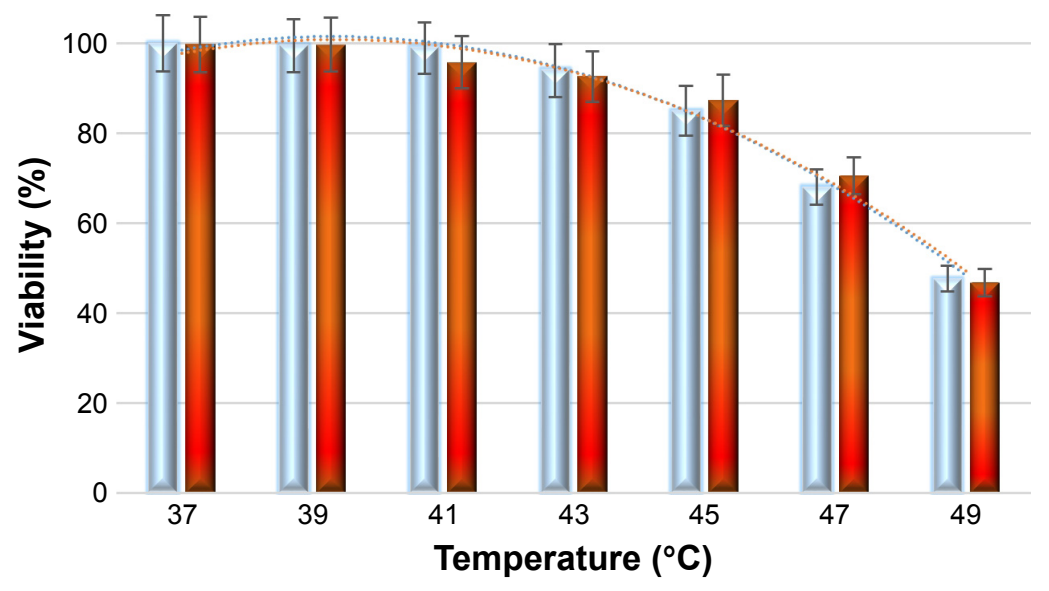

Figure 3 Cell viability after conventional hyperthermic treatment at different temperatures. Note: In light-blue are MNP-free tumor cells, and in red tumor cells incubated with MNPs. Abbreviation: MNP, magnetic nanoparticle. 


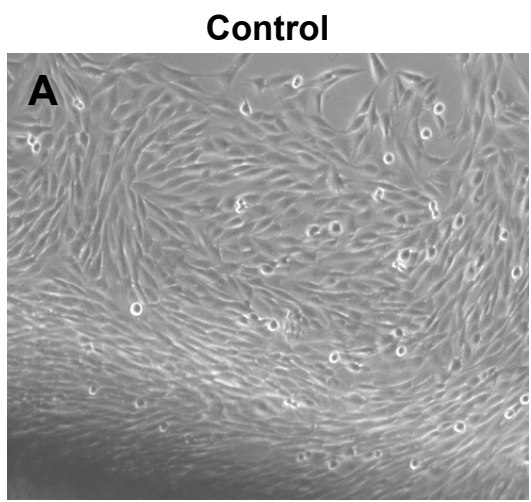

$45^{\circ} \mathrm{C}$

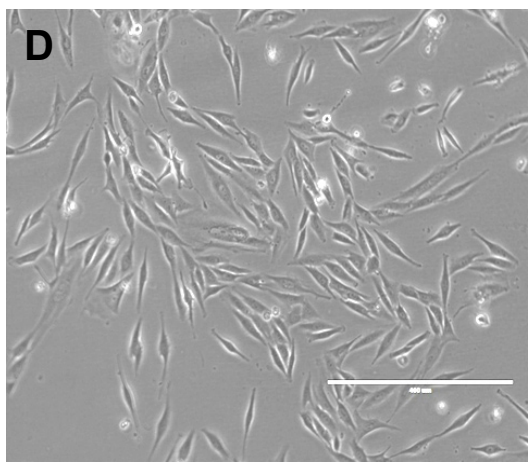

$41^{\circ} \mathrm{C}$

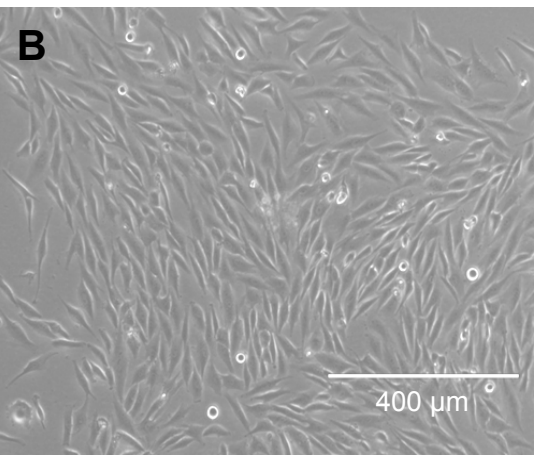

$47^{\circ} \mathrm{C}$

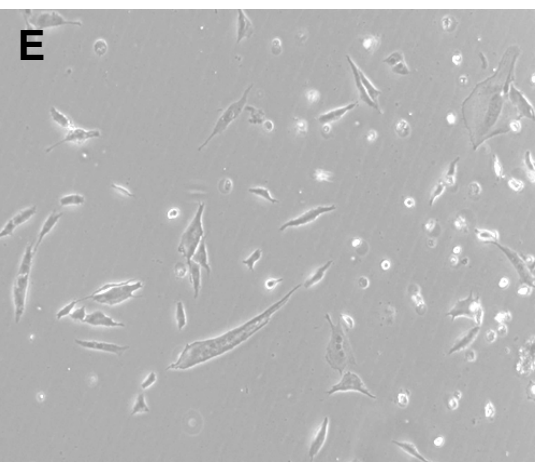

$43^{\circ} \mathrm{C}$

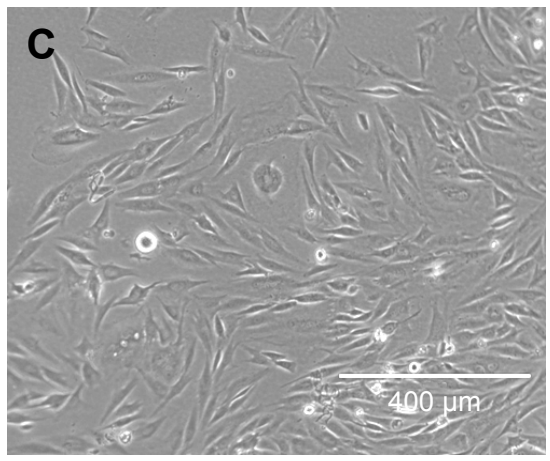

$49^{\circ} \mathrm{C}$

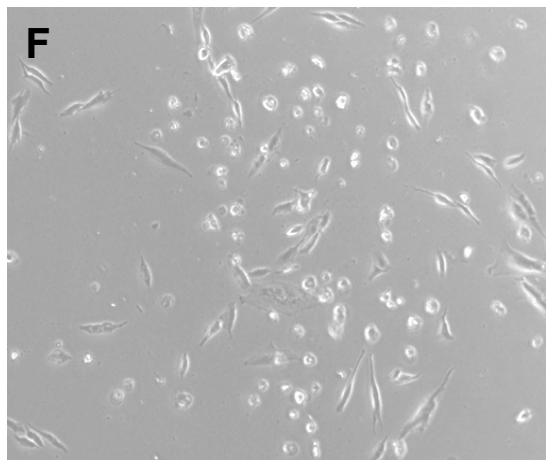

Figure 4 Tumor cells after WHT exposure.

Notes: (A) hOS cells at $37^{\circ} \mathrm{C}$ (control cells); (B-F) hOS cells subjected for one hour to WHT.

Abbreviation: WHT, water-based hyperthermia.

Figure 4 shows the images of hOS cells after WHT treatment. As temperature increases, a gradual decrease of the cell density is observed. At $47^{\circ} \mathrm{C}$ and especially at $49^{\circ} \mathrm{C}$, a consistent number of cells became near round - the final shape before detachment - indicating a very poor surface adhesion, probably due to increased cellular stress.

The hOS cells appear to be resilient to HT treatment at temperatures as high as $43^{\circ} \mathrm{C}$. However, since cell viability was assessed immediately after treatment, potential initiation of apoptosis by means of caspase activation resulting in a delayed decrease of cell survival at hours/days after exposure cannot be ruled out.

\section{MHT}

To obtain different equilibrium temperatures without modifying the applicator's power, the hOS samples were placed along the $z$-axis of the coil at different distances. Since the strength of magnetic field inside the solenoid gradually decreases from the center, along the $z$-axis direction, a negative impact on the treatment effectiveness is expected. ${ }^{25}$

We hypothesized that the capacity of MNPs to locally generate powerful AMF-triggered heating may induce different levels of cytotoxicity in hOS cells as compared to WHT, overcoming the resistance of hOS cells to WHT treatment.
Subsequently, we evaluated the survival of hOS cells exposed to MHT at approximately the same temperature as for WHT treatment.

Figure 5 presents a comparison between the two HT treatments for three given temperatures. A sharp decrease of the viability to about $54 \%$ was observed for hOS cells incubated with Fe-Cr-Nb-B MNPs after 1 hour of AMF exposure. The differences between the cellular viabilities obtained by the two HT regimes were statistically significant ( $P=0.024$; two-tails). In absolute values, there was a difference of about $16 \%$ at $47^{\circ} \mathrm{C}$.

\section{Mechanisms for different WHT and MHT cytotoxic effects}

To date, controversies exists regarding the magnitude of the cytotoxic effects induced by MHT vs WHT. By measuring the macroscopic temperature of the cell culture medium, at equal equilibrium treatment temperatures, either equal or different cytotoxic levels induced by the two HT methods were reported.

In our opinion, the explanations have to be grounded essentially on the temperature gradient established around nanoparticles and on cell-MNP interaction at nano- and sub-micrometric scale, when MNPs are placed in AMF. 


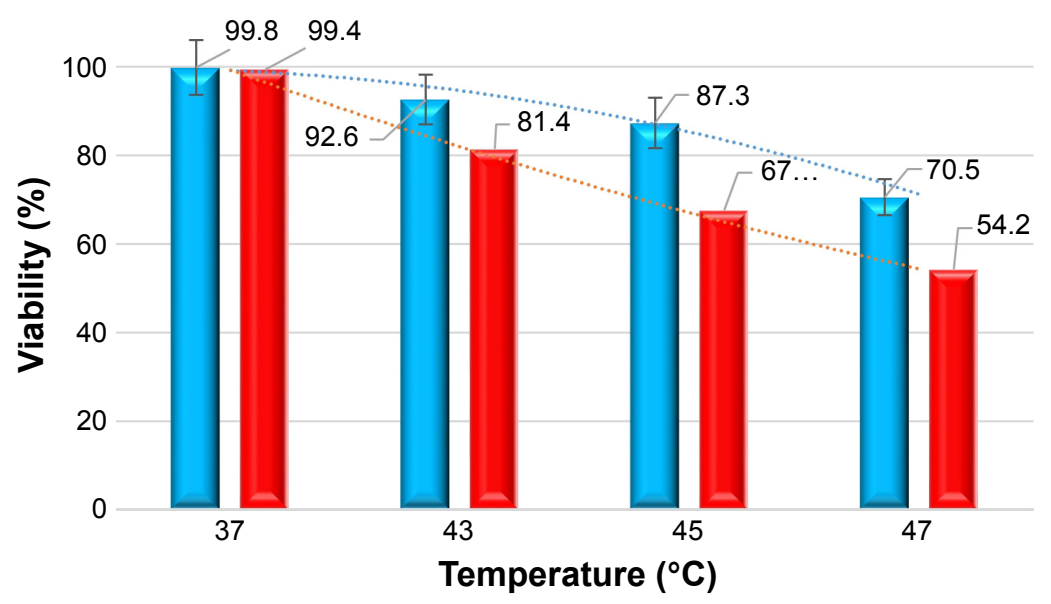

Figure 5 Comparison between the two hyperthermic regimes: blue - WHT and red - MHT. Abbreviations: MHT, magnetic hyperthermia; $\mathrm{WHT}$, water-based hyperthermia.

In this respect, several papers focusing on evaluations of the temperature developed inside the nanoparticles subjected to AMF revealed large differences between the inner temperatures of the MNPs and those of the liquid medium they heat.

In a theoretical model, Ebrahimi ${ }^{26}$ showed that in order to increase the temperature of a tumor in a desired temperature range, eg, $42^{\circ} \mathrm{C}-46^{\circ} \mathrm{C}$, the inside temperature of the nanoparticles has to be about twice higher.

In another work, Dong and Zink ${ }^{27}$ prepared mesoporous silica nanoparticles containing both superparamagnetic iron oxide nanocrystals and $\mathrm{NaYF}_{4}: \mathrm{Yb}^{3+}, \mathrm{Er}^{3+}$ optical thermometer nanocrystals in order to evaluate and monitor the temperature variation inside the magnetic nanoparticles used for magnetic hyperthermia tests. By using such an approach, they observed that the nanoparticles became much hotter inside compared with the macroscopic solution and cooled down to the temperature of the ambient fluid in seconds after the magnetic field is turned off. Quantitatively, after 5 minutes of heating in $\mathrm{AMF}$, the inner temperature of the iron oxides nanocrystals was about twice that of the solution, ${ }^{27}$ confirming the theoretical results. Thus, for a temperature of $45^{\circ} \mathrm{C}$ of the cell culture medium, about $90^{\circ} \mathrm{C}$ are expected for the inside of MNPs.

Also, Yu et $\mathrm{al}^{28}$ found that, depending on the type and concentration of MNPs, the temperature difference between the MNPs surface and bulk solution can exceed $50^{\circ} \mathrm{C}$, when an appropriate AMF is applied for 300 seconds.

Moreover, experimental determinations showed an exponential decay of the temperature ${ }^{29}$ until it equals the macroscopic temperature of the bulk solution at distances lower than $6 \mathrm{~nm}$ from the MNPs surface, ${ }^{30}$ depending on the field parameters and MNP type. Since the high temperature gradient is developed only on a very small distance from the MNPs, the cells have to get in contact with the heated MNPs to experience a cytotoxic impact higher than that induced by the bulk solution. In the case of MNPs internalized by cells, the chances to get in contact with cell organelles are increased, resulting in a high efficiency of the MHT treatment even when low MNPs concentrations are used. In this respect, Chen et $\mathrm{al}^{31}$ included in their excellent review several reports about targeted magnetic hyperthermia showing that if MNPs are combined with or incorporate into tumor cells, a high impact on the cellular viability without a perceptible macroscopic temperature rise can be achieved. Also, Marcos-Campos et al showed that the selective cytotoxicity of MNPs under an AMF could be the result of the local damage produced by MNPs. ${ }^{32}$ A reasonable explanation can be related to the very high local temperature, ie, temperature near the MNPs surface, which irreversibly affects the tumor cells (Figure 6A). On the contrary, for equal equilibrium temperatures the cytotoxic level induced by a homogeneously distributed heat (Figure 6B) will be inferior to the former setup.

Taking into account that important parts of the MNPs remain very close or even bound to the membrane due to settling on the cells' surface, many harmful effects are expected to develop within the membrane during AMF exposure. In the case of MNPs internalized by cells, it can be assumed that the highest cytotoxicity is reached for a direct contact of MNPs with cell organelles (mainly cell mitochondria and endoplasmic reticulum), the effect decreasing nonlinearly with the distance between MNPs and organelles. The precise biophysical and molecular basis of these effects (cell and cell organelle 

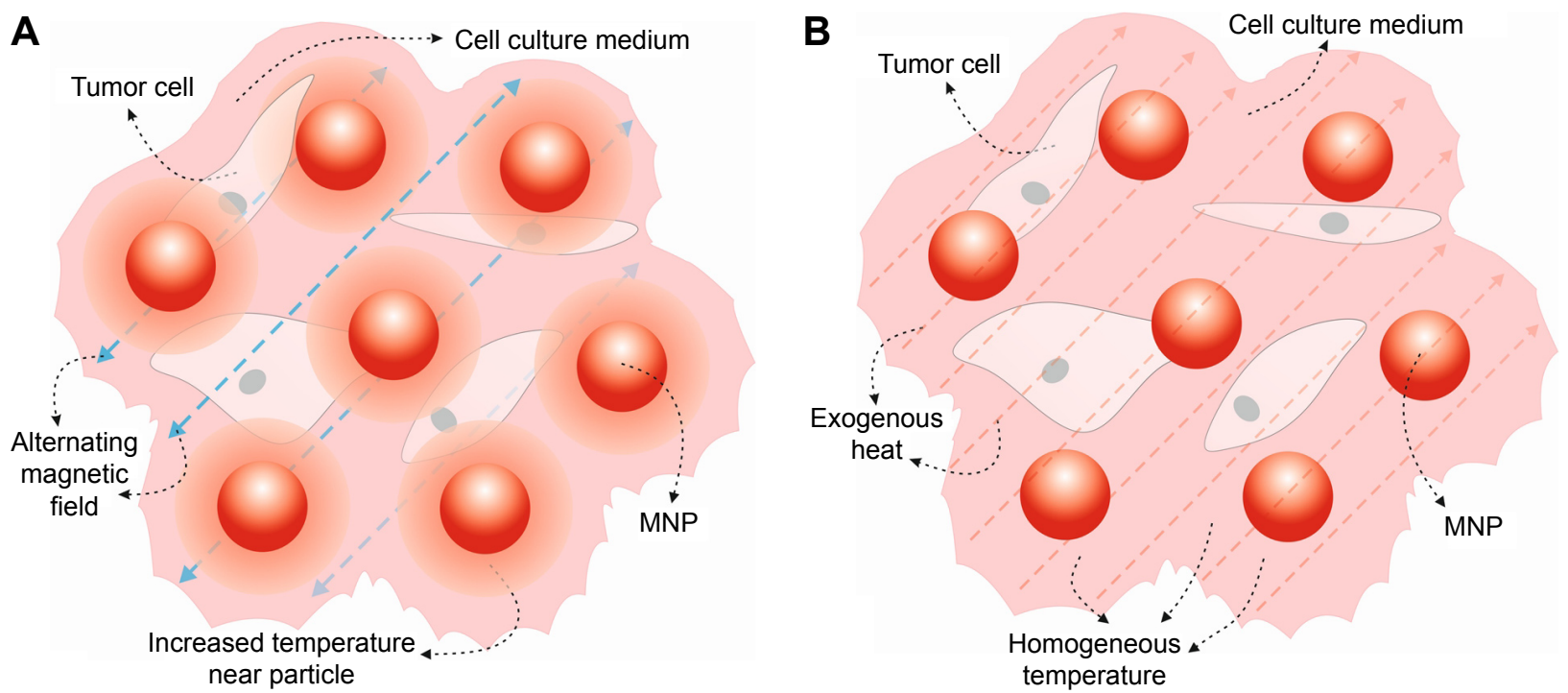

Figure 6 (A) Schematic representation of tumor cells heated by MNPs placed in AMF (MHT case). Cells close to MNPs are subjected to a higher treatment temperature due to a high gradient temperature near MNPs; (B) tumor cells and MNPs heated uniformly by exogenous heat (WHT case). There is no temperature gradient near MNPs after equilibrium macroscopic temperature is established.

Abbreviations: AMF, alternating magnetic field; MHT, magnetic hyperthermia; MNP, magnetic nanoparticle; WHT, water-based hyperthermia.

membrane disruption, and heat-induced mitochondrial and endoplasmic reticulum stress) warrants further investigation. This could derive the development of modalities for targeting the most susceptible-to-damage compartment in every cell type by using either membrane-bound or intercellular MNPs to deliver MHT treatments. However, other effects related to the dynamic state of the MNPs during the AMF exposure can also be taken into account, including perturbation of the ionic flows or transmembrane potential on cellular and/or organelle membranes.

As regards WHT, the tests described in literature assumed a water immersion of the wells or test tubes loaded with tumor cells. Generally, the volumes of the samples were below $10 \mathrm{~mL},,^{9,10,13}$ and therefore quick heating of the cells was achieved with such experimental setup.

In this work, we also wanted to experimentally check if there were any differences between the heating curves recorded after subjecting $2 \mathrm{~mL}$ cell culture wells, filled with $1 \mathrm{~mL}$ culture medium and Fe-Cr-Nb-B MNPs, to both HT treatments. The WHT assumed a direct contact of the wells with heated water in the thermostated water bath whereas the MHT treatment followed the initial protocol described above, except for tumor cells. Temperature was recorded with the optical thermometer.

The results pointed out a superior heating rate of the WHT compared with MHT. Specifically, the WHT heating rate was 9.3 times higher, calculated from the straight line of the plot, ie, from starting points to $36^{\circ} \mathrm{C}$ (Figure 7).
However, the average heating rate of WHT, calculated from the starting points to $43^{\circ} \mathrm{C}$ (temperature that was chosen arbitrarily as being near the first overlapping points of the curves) was only 6.8 times bigger as compared to MHT.

In our experimental setup, in the case of MHT, about 24 minutes were needed to increase temperature from $37^{\circ} \mathrm{C}$ to $43^{\circ} \mathrm{C}$ within 60 minutes of exposure. Conversely, in the case of WHT only 4 minutes was needed for the same temperature increase. As a result, during MHT exposure the culture medium experienced a temperature equal or

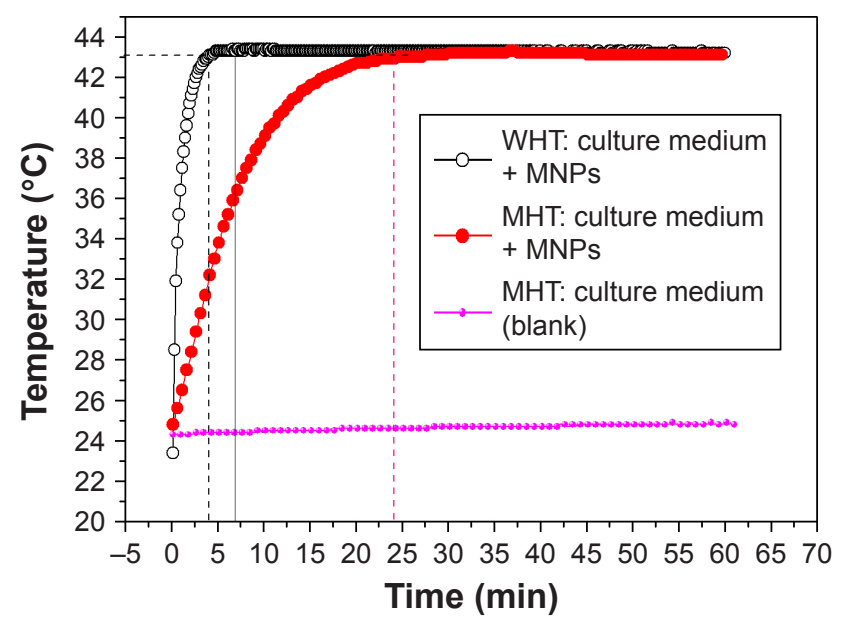

Figure 7 Temperature curves for WHT and MHT.

Notes: The heating rate for $\mathrm{WHT}$ was $0.26^{\circ} \mathrm{C} / \mathrm{s}$ vs $0.028^{\circ} \mathrm{C} / \mathrm{s}$ for $\mathrm{MHT}$. The average heating rate for $\mathrm{WHT}$ was $0.082^{\circ} \mathrm{C} / \mathrm{s}$ and $0.012^{\circ} \mathrm{C} / \mathrm{s}$ for $\mathrm{MHT}$.

Abbreviations: $\mathrm{MHT}$, magnetic hyperthermia; MNPs, magnetic nanoparticles; WHT, water-based hyperthermia. 
higher than $43^{\circ} \mathrm{C}$ for only $60 \%$ of the total exposure time as compared to $93 \%$ for WHT. If this observed difference would be translated to cell-based comparative HT experiments, a higher cytotoxic impact would be expected from WHT. However, the literature did not report a superior efficiency of the WHT. Accordingly, even if the exposure time to WHT treatment at a killing temperature, eg, $43^{\circ} \mathrm{C}$, is much more increased, the final cytotoxic effects are at most equal to those induced by the MHT treatment. The immediate conclusion is that MHT is superior in terms of killing efficiency compared with WHT.

Yet, the cytotoxicity difference between the two HT methods could be perhaps canceled if the temperature of the treatments is kept near the highest level for both methods, ie, $46^{\circ} \mathrm{C}-47^{\circ} \mathrm{C}$, when the killing effect potential is near maximum for both. In this case, probably only the exposure time could make clear any difference between them, ie, shorter exposure times could establish the superior efficiency of the MHT. Also, if MHT is based on low concentrations of MNPs characterized by low-to-medium Specific Absorption Rate/ Specific Power Absorption (SAR/SPA), and MNPs are submitted to inadequate AMF, a considerable latency for getting to a preferred treatment temperature, eg, $43^{\circ} \mathrm{C}$, is introduced. Consequently, the treatment temperature induced in the bulk solution will in fact be below $43^{\circ} \mathrm{C}$ for long time periods during $\mathrm{AMF}$ exposure. Comparatively, the time needed to get to equilibrium temperature is more reduced for WHT, especially for low sample volumes when the heat transfer between water bath and sample is very fast. Shortly, there would be a longer heat exposure at $43^{\circ} \mathrm{C}$ for the samples subjected to WHT, and therefore even if the MHT treatment would be locally more efficient, similar cytotoxic effects could be obtained.

However, there will always be an additional interplay between cell type, cell density, MNP type, concentration and SAR(SPA), and field parameters of the heating equipment that decisively impact the efficiency of the HT methods. Since many variable parameters have to be taken into account for MHT, including a distance-dependent cytotoxic influence of the MNPs, it is possible that the two methods are equally efficient in particular conditions. Therefore, the apparently divergent data reported by different teams could be explained by the variability of experimental conditions. But, in any case, there will always be an increased temperature near MNPs subjected to AMF, either well dispersed or organized in clusters, inducing an enhanced cytotoxicity on the cells tightly bound to MNPs or placed in their very close proximity.

It is also worth noting that before applying an MHT treatment to a specific cancerous cell type, it would be of interest to establish a priori the optimum killing temperature using the WHT method. This would enable better dosing of the magnetic material to be introduced in tumor for further in vivo experiments. Enhanced optimization of the time required to adjust the applicator's power in order to generate appropriate magnetic fields for MNP activation is another possible advantage.

Finally, we can speculate based on present results that a highly homogeneous distribution of MNPs among tumor cells along with their translational magnetomechanical movement under very low-frequency magnetic fields, eg, 1-10 Hz, applied between short MHT heating cycles could be used as a modality to increase the contact area between MNPs and surrounding cells, and could boost the MHT efficiency.

\section{Conclusion}

In this work, a comparative analysis between MHT and WHT was performed. MHT was found to be more efficient in terms of cytotoxicity compared with the latter. The cytotoxicity difference between the two HT methods can be related to the AMF-heated MNPs that induced higher temperature levels near nanoparticles compared with equilibrium temperature of the bulk cell culture medium surrounding the MNPs. Consequently, it was assumed that for identical exposure time to specific treatment temperature, a higher damage of the cancerous cells bound to or very close to the MNPs can be achieved using MHT compared with WHT. We propose that WHT could be used as a method to establish the temperature threshold that is cytotoxic to a particular cell type to further calibrate the MHT method. The multiparametric variability of MHT exposure conditions closely influences MNPs capability to induce local heating at cellular and subcellular level. Therefore, the results of different experiments reported should be interpreted in the context of the specific experimental setup.

\section{Acknowledgment}

This work was supported by the Nucleu Program - Project PN 18060101.

\section{Disclosure}

The authors report no conflicts of interest in this work.

\section{References}

1. Adam C, Janusz S, Marek K. Hyperthermia - description of a method and a review of clinical applications. Rep Pract Oncol Radiother. 2007; 12(5):267-275.

2. Wang C, Hsu CH, Li Z, et al. Effective heating of magnetic nanoparticle aggregates for in vivo nano-theranostic hyperthermia. Int J Nanomedicine. 2017;12:6273-6287. 
3. Jurek PM, Zabłocki K, Waśko U, Mazurek MP, Otlewski J, Jeleń F. Anti-FGFR1 aptamer-tagged superparamagnetic conjugates for anticancer hyperthermia therapy. Int J Nanomedicine. 2017;12:2941-2950.

4. Kalber TL, Ordidge KL, Southern P, et al. Hyperthermia treatment of tumors by mesenchymal stem cell-delivered superparamagnetic iron oxide nanoparticles. Int J Nanomedicine. 2016;11:1973-1983.

5. Hedayatnasab Z, Abnisa F, Daud WMAW. Review on magnetic nanoparticles for magnetic nanofluid hyperthermia application. Mater Des. 2017;123:174-196.

6. Sohail A, Ahmad Z, Bég OA, Arshad S, Sherin L. A review on hyperthermia via nanoparticle-mediated therapy. Bull Cancer. 2017; 104(5):452-461.

7. Dariush S, Nicolae V. Cancer treatment with hyperthermia. In: O Ozdemir, editor. Current Cancer Treatment - Novel Beyond Conventional Approaches. London: InTech; 2011:455-474.

8. Dewhirst MW, Vujaskovic Z, Jones E, Thrall D. Re-setting the biologic rationale for thermal therapy. Int J Hyperthermia. 2005;21(8): 779-790.

9. Rodríguez-Luccioni HL, Latorre-Esteves M, Méndez-Vega J, et al. Enhanced reduction in cell viability by hyperthermia induced by magnetic nanoparticles. Int J Nanomedicine. 2011;6:373-380.

10. Sanz B, Calatayud MP, Torres TE, Fanarraga ML, Ibarra MR, Goya GF. Magnetic hyperthermia enhances cell toxicity with respect to exogenous heating. Biomaterials. 2017;114:62-70.

11. Chan DCF, Kirpotin DB, Bunn PA Jr. Synthesis and evaluation of colloidal magnetic iron oxides for the site-specific radio frequency-induced hyperthermia of cancer. J Magn Magn Mater. 1993;122:374.

12. Wilhelm C, Fortin JP, Gazeau F. Tumour cell toxicity of intracellular hyperthermia mediated by magnetic nanoparticles.JNanosci Nanotechnol. 2007;7(8):2933-2937.

13. Calatayud MP, Soler E, Torres TE, et al. Cell damage produced by magnetic fluid hyperthermia on microglial BV2 cells. Sci Rep. 2017; $7(1): 8627$.

14. Chiriac H, Lupu N, Lostun M, Ababei G, Grigoraş M, Dănceanu C. Low $\mathrm{T}_{\mathrm{C}} \mathrm{Fe}-\mathrm{Cr}-\mathrm{Nb}-\mathrm{B}$ glassy submicron powders for hyperthermia applications. J Appl Phys. 2014;115(17):520.

15. MG-63 Cell Line human. St. Louis, MO: Sigma. Available from: https://www.sigmaaldrich.com/catalog/product/sigma/cb_86051601? lang=en\&region=RO. Accessed June 28, 2018.

16. Elengoe A, Hamdan S. Heat sensitivity between human normal liver (WRL-68) and breast cancer (MCF-7) cell lines. J Biotechnol Lett. 2013; 4:45-50.

17. Armour EP, Mceachern D, Wang Z, Corry PM, Martinez A. Sensitivity of human cells to mild hyperthermia. Cancer Res. 1993;53(12) 2740-2744.
18. Mohseny AB, Machado I, Cai Y, et al. Functional characterization of osteosarcoma cell lines provides representative models to study the human disease. Lab Invest. 2011;91(8):1195-1205.

19. Ito A, Shinkai M, Honda H, Kobayashi T. Medical application of functionalized magnetic nanoparticles. J Biosci Bioeng. 2005; 100(1):1-11.

20. Araújo-Neto RP, Silva-Freitas EL, Carvalho JF, et al. Monodisperse sodium oleate coated magnetite high susceptibility nanoparticles for hyperthermia applications. J Magn Magn Mater. 2014;364:72-79.

21. Nikiforov VN. Magnetic induction hyperthermia. Russian Physics Journal. 2007;50(9):913-924.

22. Hergt R, Dutz S, Müller R, Zeisberger M. Magnetic particle hyperthermia: nanoparticle magnetism and materials development for cancer therapy. Journal of Physics: Condensed Matter. 2006;18(38): S2919-S2934.

23. Zhang L-Y, Gu H-C, Wang X-M. Magnetite ferrofluid with high specific absorption rate for application in hyperthermia. J Magn Magn Mater. 2007;311(1):228-233.

24. Kalamida D, Karagounis IV, Mitrakas A, Kalamida S, Giatromanolaki A, Koukourakis MI. Fever-range hyperthermia vs. hypothermia effect on cancer cell viability, proliferation and HSP90 expression. PLoS One. 2015;10(1):e0116021.

25. Tang Y-Dong, Flesch RCC, Zhang C, Jin T. Numerical analysis of the effect of non-uniformity of the magnetic field produced by a solenoid on temperature distribution during magnetic hyperthermia. J Magn Magn Mater. 2018;449:455-460.

26. Ebrahimi M. On the temperature control in self-controlling hyperthermia therapy. J Magn Magn Mater. 2016;416:134-140.

27. Dong J, Zink JI. Taking the temperature of the interiors of magnetically heated nanoparticles. ACS Nano. 2014;8(5):5199-5207.

28. Yu L, Liu J, Wu K, Klein T, Jiang Y, Wang JP. Evaluation of hyperthermia of magnetic nanoparticles by dehydrating DNA. Sci Rep. 2014 4:7216.

29. Riedinger A, Guardia P, Curcio A, et al. Subnanometer local temperature probing and remotely controlled drug release based on azo-functionalized iron oxide nanoparticles. Nano Lett. 2013;13(6):2399-2406.

30. Dias JT, Moros M, del Pino P, Rivera S, Grazú V, de La Fuente JM DNA as a molecular local thermal probe for the analysis of magnetic hyperthermia. Angew Chem Int Ed Engl. 2013;52(44):11526-11529.

31. Chen L, Chen C, Wang P, Song T. Mechanisms of Cellular Effects Directly Induced by Magnetic Nanoparticles under Magnetic Fields. J Nanomater. 2017;2017(48):1-13.

32. Marcos-Campos I, Asín L, Torres TE, et al. Cell death induced by the application of alternating magnetic fields to nanoparticle-loaded dendritic cells. Nanotechnology. 2011;22(20):205101.
International Journal of Nanomedicine

\section{Publish your work in this journal}

The International Journal of Nanomedicine is an international, peerreviewed journal focusing on the application of nanotechnology in diagnostics, therapeutics, and drug delivery systems throughout the biomedical field. This journal is indexed on PubMed Central, MedLine, CAS, SciSearch $®$, Current Contents $\AA /$ Clinical Medicine,

\section{Dovepress}

Journal Citation Reports/Science Edition, EMBase, Scopus and the Elsevier Bibliographic databases. The manuscript management system is completely online and includes a very quick and fair peer-review system, which is all easy to use. Visit http://www.dovepress.com/ testimonials.php to read real quotes from published authors. 